\title{
Quantum Dot-Based Probes for Labeling and Imaging of Cells that Express Matrix Metalloproteinases
}

David Benito-Alifonso, ${ }^{\dagger}$ Barbara Richichi, ${ }^{\ddagger}, \|_{\odot}$ Veronica Baldoneschi, ${ }^{\ddagger}, \|$ Monica Berry, ${ }^{\dagger}$ Marco Fragai, ${ }^{\ddagger}, \S_{\odot}$

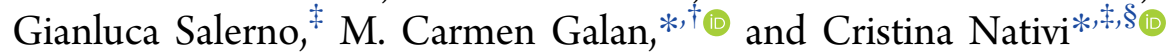

†School of Chemistry, University of Bristol, Cantock’s Close, BS8 1TS Bristol, U.K.

${ }^{\ddagger}$ Department of Chemistry, University of Florence, via della Lastruccia, 3-13, Sesto Fiorentino, Florence 50019, Italy

${ }^{\S}$ CeRM, University of Florence, via L. Sacconi, 6, Sesto Fiorentino, Florence 50019, Italy

Supporting Information

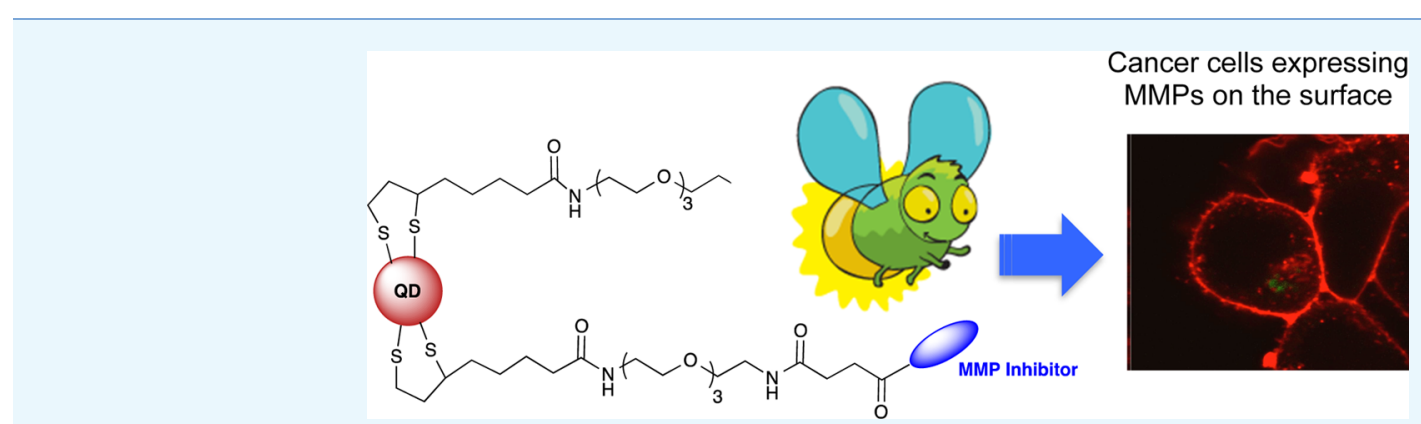

ABSTRACT: The practical synthesis of novel multivalent fluorescent quantum-dot-based probes to target cellular matrix metalloproteinases (MMPs) (MT-MMPs) is reported. We show that these probes, which are decorated with a nanomolar water-soluble MMP inhibitor, can be used to label preferentially the surface of cancer cells that are known to express MMPs while no binding was observed on cells that do not.

\section{INTRODUCTION}

Matrix metalloproteinases (MT-MMPs) are a family of structural and functional-related $\mathrm{Zn}$-containing endopeptidases almost ubiquitously expressed and largely involved in physiological processes. When abnormally expressed, however, they trigger many pathological events including cancer, where the strict physiological control of MMPs' activity is disrupted, thus promoting tumor cell migration from original sites and invasion of distant organs. ${ }^{1-3}$

The inhibition of MMPs has been an extensively pursued therapeutic strategy to treat cancer but at present, MMPs are considered elusive targets for they are characterized by similar active sites able to adapt for binding ligands. Nonetheless, a large number of synthetic inhibitors were published, and some of them entered clinical trials. The failure of these trials was mainly ascribed to the lack of solubility in water and poor bioavailability of all of the inhibitors tested. The latter is also responsible for severe side-effects in the case of chronic treatments $^{4,5}$ and explains why no synthetic MMP inhibitor (MMPI) is currently used clinically for cancer treatment. ${ }^{6}$ The recent development of nanomolar, water-soluble $\mathrm{MMPIs}^{7}$ (Figure 1) certainly represents a step forward in the use of synthetic inhibitors for MMPs' targeting and in vivo inhibition. The lack of selectivity, however, still impairs their use in therapy.

Among MMPs, MMP-14 is one of the six MMPs referred to as membrane-anchored MMPs (MT-MMPs). MMP-14 is

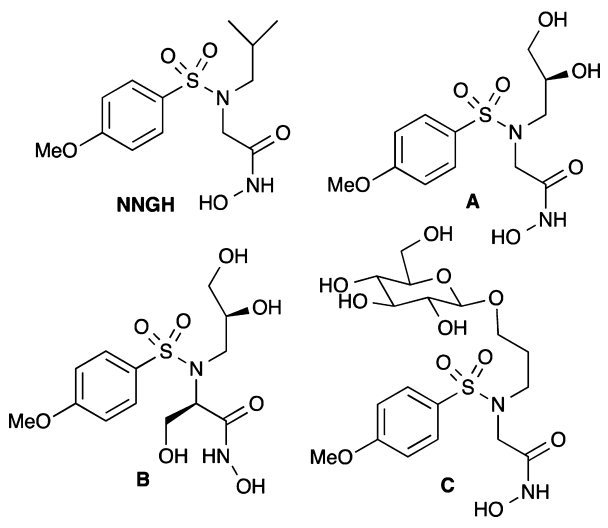

Figure 1. Structure of ( $N$-isobutyl- $N$-(4-methoxyphenylsulfonyl)glycyl hydroxamic acid) (NNGH) and of water-soluble MMPIs AC. In $\mathbf{A}$ and $\mathbf{B}$, the isobutyl residue of $\mathrm{NNGH}$ is replaced by a dihydroxyl residue and $\mathbf{C}$ by a glucose moiety.

correlated with angiogenesis, ${ }^{8}$ and a high expression of MMP14 is also associated with a poor prognosis in breast cancer patients, ${ }^{9}$ with lymph node metastasis and with malignant brain tumors ${ }^{10}$ and melanoma. ${ }^{11}$ The pivotal role played by

Received: April 3, 2018

Accepted: June 21, 2018

Published: August 23, 2018 
Scheme 1. (i) See Ref 5; (ii) $\mathrm{Ph}_{3} \mathrm{P}$, (Diisopropyl azodicarboxylate), THF, $70{ }^{\circ} \mathrm{C}, 86 \%$; (iii) LiOH (1 M, $\left.\mathrm{H}_{2} \mathrm{O}\right)$, THF, rt, $1 \mathrm{~h}$, >90\%; (iv) TBTU, NMM, BnONH 2 , rt, 78\%; (v) $\mathrm{H}_{2}$, Pd/C 10\%, THF- $\mathrm{H}_{2} \mathrm{O}$, rt, 2 h, 97\%, (1a, See Supporting Information); and (vi) TFA, $\mathrm{CH}_{2} \mathrm{Cl}_{2}, \mathrm{rt}, 2 \mathrm{~h},>90 \%$

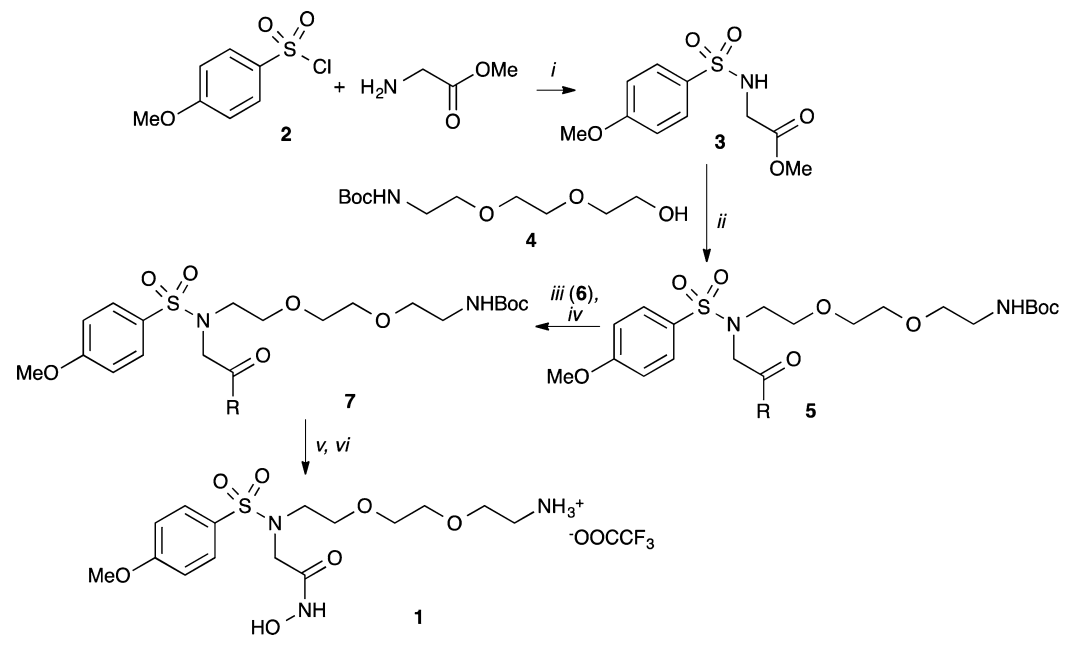

MMP-14 and by MT-MMPs, in general, is mainly because of their localization at the focal cell surface, where they create the proteolytic favorable conditions for cancer cells to progress and invade the extracellular matrix. ${ }^{12}$ The association and pathological correlation between the high expression of MMP-14 and a shortened survival in cancer patients make the MT-MMPs targeting and imaging a goal of primary importance for the early diagnosis and monitoring of MMP-14mediated tumors. MMP-14 is highly expressed in a number of invasive cancer cell lines such as MDA-MB231 (triple negative breast cancer cell) ${ }^{13}$ and also present in HeLa (cervical cancer cell line), ${ }^{14}$ whereas not found in MCF-7 (breast adenocarcinoma cell line). ${ }^{13}$

To date, MMP imaging has been reported with either fluorescent molecules or labeled MMPIs, for preclinical applications and, more recently, in some animal models. ${ }^{15-18}$ In recent years, luminescent semiconductors, quantum dots (QDs), have emerged as versatile nanoplatforms for nonisotopic detection suitable to live cells, in vivo imaging, and immunoassays because of their superior photostability to organic fluorophores and dyes, in addition to their bright visible emission, narrow emission spectra, and common excitation. ${ }^{17-20}$ Capitalizing on the extensive experience of some of us on the synthesis and functionalization of QDs, we decorated these stable fluorescent nanoparticles with watersoluble MMPI residues to obtain a probe to visualize cancer cells by targeting MT-MMPs expressed on their surface.

\section{RESULTS AND DISCUSSION}

The MMPI selected to conjugate to the surface of the QDs, $\mathbf{1})^{23}$ is structurally related to NNGH (Scheme 1) and displays a triethylene glycol residue linked to sulfonamidic nitrogen (Scheme 1). This polar linker accounts for a good solubility in water of the inhibitor. The replacement of the triethylene glycol residue with an aliphatic chain of the same length was also considered, but this structural modification impaired the water solubility. The synthesis of 1 was performed by reacting the commercially available sulfonyl chloride $\mathbf{2}$ with methyl glycinate to yield the corresponding sulfonamide derivative 3, which was subsequently reacted with triethylene glycol 4 under Mitsunobu reaction conditions to yield 5 (86\% over the 2 steps) (Scheme 1). Ester 5 was hydrolyzed $[\mathrm{LiOH}$, tetrahydrofuran (THF), rt, quantitative yield], and the resulting acid 6 , activated with [2-(1H-bezotriazole-1-yl)1,1,3,3-tetramethylaminium tetrafluoborate (TBTU) and ( $\mathrm{N}$-methyl morfoline) (NMM), was treated with $\mathrm{NH}_{2} \mathrm{OBn}$ in dry $\mathrm{N}, \mathrm{N}$-dimethylfomamide to give benzyl hydroxamate 7 (78\%). After hydrogenation ( $\left.\mathrm{Pd} / \mathrm{C}, \mathrm{THF}-\mathrm{H}_{2} \mathrm{O}>90 \%\right)$ and removal of the Boc protecting group [trifluoroacetic acid (TFA), dichloromethane, rt], inhibitor 1 was isolated quantitatively. $^{21}$

The inhibition constant of $\mathbf{1}$ toward MMP-12 $2^{a, 24}$ was evaluated in vitro by a spectrofluorimetric assay. ${ }^{5}$ The $K_{\mathrm{i}}$ value obtained $(20 \pm 9 \mathrm{~nm})$ confirmed that the very good affinity of the NNGH is preserved for $\mathbf{1}$ and that, as expected, ${ }^{13}$ the ethylene glycol portion is marginally involved in the binding.

Monodispersed trioctylphosphine oxide-coated $\mathrm{CdSe} / \mathrm{ZnS}$ nanoparticles were prepared, as previously reported ${ }^{21,22}$ (see the Supporting Information). Ligand exchange under reductive conditions with a 2:3 mixture of lipoic acid-PEG-COOH 8 (for biomolecule conjugation) and lipoic acid-PEG-OH 9 (as spacer) in water/EtOH as the solvent gave $70 \%$ acidfunctionalized QD-70COOH (hydrodynamic size: $9.0 \pm 0.2$ $\mathrm{nm}$ ) (Figures 2 and S1A in the Supporting Information). It was deemed necessary to extend the linkers grafted on QD$70 \mathrm{COOH}$ and to enhance the nanoparticle water solubility after MMPI conjugation (see the Supporting Information for details). ${ }^{25}$ Thus, the treatment of QD-70COOH with diaminotetraethylene glycol using 1-ethyl-3-(3-dimethylaminopropyl)carbodiimide hydrochloride (EDC. $\mathrm{HCl})$ in phosphate-buffered saline (PBS), followed by further functionalization of the resulting terminal amine groups with MMPI 1 upon reaction with EDC and succinic anhydride in PBS as solvent, afforded QD-1 (hydrodynamic size $304 \pm 18 \mathrm{~nm}$ ) nanoparticles, which are soluble in and stable in water solution for 2 days after sonication (Figure 2 and Supporting Information for details).

Toxicity studies for MMPI $1(10 \mu \mathrm{g} / \mathrm{mL})$ and QD-1 $(1 \mu \mathrm{g} /$ $\mathrm{mL}$ ) were then carried out in HeLa (human cervical) and MCF-7 and MDA-MB-231 (human breast) cancer cells (see the Supporting Information for full experimental details). Cultures were exposed to these compounds for $72 \mathrm{~h}$. Cell viability and metabolic competence were assessed by Alamar Blue $(\mathrm{AB})$, and the number of live cells with Calcein $\mathrm{AM}$ and 
<smiles>CNCCCOCCNC(=O)CCC(=O)NCCO[C@H](C)CCN(CC(=O)NO)S(=O)(=O)c1ccc(OC)cc1</smiles>

Figure 2. Structure of lipoic acid derivatives 8 and 9 and of QDs$70 \mathrm{COOH}$ and QD-1.

of dead cells were assessed using Sytox. The ratio of $\mathrm{AB} /$ Calcein affords a measure of metabolic function per cell, providing a metric to compare treated cells against untreated cells (Figure S5 in the Supporting Information). In the case of MCF-7 and MDA, neither the number of live cells or dead cells was significantly affected by the treatment with a solution of 1 or QD-1 (Kruskal-Wallis ANOVA, see the Supporting Information). In MCF7 cell cultures treated with QD-1, however, the reductive metabolism was significantly increased compared to untreated controls $(p<0.001)$ (Figure S5 in the Supporting Information).

To evaluate the potential of QD-1 in targeting and visualizing MMP-overexpressing cancer cells with respect to other cells, the two human breast carcinoma cell lines (MCF-7 and MDA-MB-231) and the human cervix epitheloid carcinoma cell line (HeLa) were incubated for a period of 2 and $4 \mathrm{~h}$ with QD-1 $(200 \mu \mathrm{g} / \mathrm{mL})$ or $2 \mathrm{~h}$ exposure to a mixture of QD-1 $(200 \mu \mathrm{g} / \mathrm{mL})$ and $\mathbf{1}(10 \mu \mathrm{g} / \mathrm{mL})$ and taken directly to be imaged. Of note, QD-1 was not taken up intracellularly, as determined by confocal microscopy, by any of the cell lines studied after 2 or $4 \mathrm{~h}$ exposure. However, fluorescent labeling by QD-1 was predominantly found on the surface of HeLa and MDA cells, which are known to express MMPs including MMP-14 (Figures 3 and S6-S8). ${ }^{13,14}$ Furthermore, colocalization experiments using CellMask red staining to label the cell membrane $^{18}$ confirmed that the QDs decorated with the MMPI 1 (QD-1) were mostly bound to the cell surface. Quantification of the fluorescence labeling was carried out for each cell line (see the Supporting Information for details). In general, significant differences among mean fluorescent intensities were observed when comparing untreated cells with QD-1 exposed cells. Interestingly, an 18\% enhancement of fluorescence is observed only for MDA-MB-31 and HeLa cells, when cells are incubated with QD-1 in conjunction with monovalent MMPI 1 for $2 \mathrm{~h}$, further supporting that the probes are selective for these MMP-expressing cancer cell lines. These results suggest that the probes can differentiate between
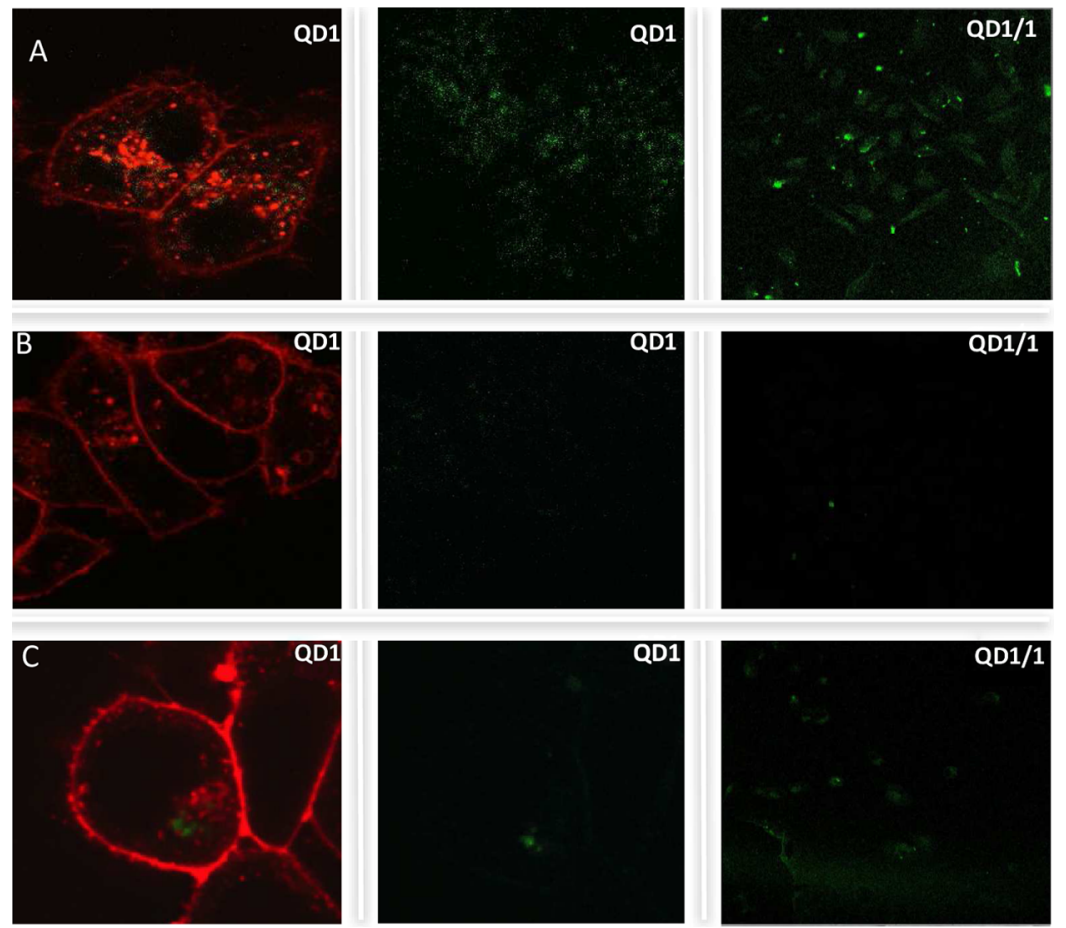

Figure 3. Confocal microscopy images showing (A) QD-1 localization on HeLa cell surface after $2 \mathrm{~h}$ incubation in the absence and presence of $\mathbf{1}$; (B) no probe incorporation on MCF-7 cells after $2 \mathrm{~h}$ incubation; and (C) QD-1 cell-surface membrane localization on MDA-MB-31 cells after $2 \mathrm{~h}$ incubation in the absence and presence of $\mathbf{1}$. CellMask tracker $=$ red, QD-1 $=$ green. 
cancer cell lines and as such could potentially be used to target and image cell-surface MMP receptors.

\section{CONCLUSIONS}

In conclusion, the practical and expedient synthesis of novel QD-based fluorescent probes to target cellular MT-MMPs is reported. The probes bear a novel and water-soluble MMPI which was prepared readily for nanoparticle conjugation. We showed that the probes do not elicit any significant toxicity in any of the cells evaluated. More excitingly, confocal microscopy experiment showed that the MMPI probes (QD1) bind preferentially to the surface of cancer cell lines that are known to express MMPs (e.g., HeLa and MDA-MB-231), whereas no binding was observed on cells that do not (MCF7 ), suggesting that these fluorescent probes can discern between cell lines and thus could be utilized as diagnostic tools.

\section{MATERIALS AND METHODS}

Chemicals were purchased and used without further purification. Dry solvents were obtained by distillation using standard procedures or by passage through a column of anhydrous alumina using equipment from Anhydrous Engineering (University of Bristol) based on the Grubbs' design. Reactions requiring anhydrous conditions were performed under $\mathrm{N}_{2}$; glassware and needles were either flame-dried immediately prior to use or placed in an oven $\left(150{ }^{\circ} \mathrm{C}\right)$ for at least $2 \mathrm{~h}$ and allowed to cool in desiccators or under reduced pressure. Liquid reagents, solutions, or solvents were added via syringe through rubber septa; solid reagents were added via Schlenk-type adapters. Teflon rings were used between the joints of the condensers and round-bottom flasks. Reactions were monitored by thin layer chromatography on Kieselgel 60 F254 (Merck), with UV light $(254 \mathrm{~nm})$ detection and by charring with $10 \%$ sulfuric acid in ethanol. Flash column chromatography was performed using silica gel [Merck, 230400 mesh $(40-63 \mu \mathrm{m})]$. Extracts were concentrated in vacuum using both a Büchi rotary evaporator (bath temperatures up to $40{ }^{\circ} \mathrm{C}$ ) at a pressure of $15 \mathrm{mmHg}$ (diaphragm pump) or $0.1 \mathrm{mmHg}$ (oil pump), as appropriate, and a high vacuum line at room temperature. Water-soluble compounds were freeze-dried on a Lytotrap Plus (LTE Scientific LTD). ${ }^{1} \mathrm{H}$ $\mathrm{NMR}$ and ${ }^{13} \mathrm{C}$ NMR spectra were measured in the solvent stated at 400,500, or $600 \mathrm{MHz}$. Chemical shifts are quoted in parts per million from residual solvent peak $\left(\mathrm{CDCl}_{3}:{ }^{1} \mathrm{H}-7.26\right.$ ppm and $\left.{ }^{13} \mathrm{C}-77.16 \mathrm{ppm}\right)$ and coupling constants $(J)$ given in hertz. Multiplicities are abbreviated as b (broad), s (singlet), d (doublet), $\mathrm{t}$ (triplet), q (quartet), $\mathrm{m}$ (multiplet), or combinations thereof. Dynamic light scattering (DLS) and zeta analysis are carried out using Malvern Instruments, Nano_S90 Red Laser model ZEN1690 for DLS, and Nano-Z ZEN $\overline{2} 600$ for zeta potential.

Cell Culture. Two human breast carcinoma cell lines, MCF-7 and MDA-MB-231, were used in this study, as well as the human cervix epitheloid carcinoma cell line HeLa. All cells were purchased from ECCAC, Public Health England. MCF-7 cells were maintained in minimal essential medium, MDA in Dulbecco's modified Eagle's medium (DMEM) with $4.5 \mathrm{~g}$ of glucose/L and HeLa in DMEM with $1 \mathrm{~g}$ of glucose/L. All media (Thermo-Fisher) were supplemented with antibioticantimycotic [and $10 \%(\mathrm{v} / \mathrm{v})$ fetal bovine serum (ThermoFisher)] for routine culture.
Incubation of QD-1 with Cells. Confluent cultures were detached from the surface using trypsin (Tryp LE Express) and plated at $2 \times 10^{4}$ cells/well in either Petri dishes (Mat-Tek 35 $\mathrm{mm}$, with $14 \mathrm{~mm}$ glass microwell) for imaging or 96-well plates for other tests. All cell culture media and additives were purchased from Invitrogen, Life Technologies.

MCF7, MDA-MB-231, and HeLa cells were incubated for $30 \mathrm{~min}, 1,2$, and $4 \mathrm{~h}$ with QD-1 $(200 \mu \mathrm{g} / \mathrm{mL})$, followed by extensive PBS washes, and imaged immediately thereafter in the imaging buffer. It was determined that although minimum labeling was observed at $30 \mu \mathrm{g} / \mathrm{mL}$ of QD-1, $200 \mu \mathrm{g} / \mathrm{mL}$ was optimum for effective labeling. Higher concentrations of QD-1 were not used to avoid nanoparticle clustering and precipitation of the stocks. It was also observed that $2 \mathrm{~h}$ incubation was optimum for the effective cell labeling.

Incubation of QD-1 and MMPI 1 with Cells. Confluent cultures were detached from the surface using trypsin (Tryp LE Express) and plated at $2 \times 10^{4}$ cells/well in either Petri dishes (Mat-Tek $35 \mathrm{~mm}$, with $14 \mathrm{~mm}$ glass microwell) for imaging or 96-well plates for other tests. All cell culture media and additives were purchased from Invitrogen, Life Technologies.

MCF7, MDA-MB-231, and HeLa cells were incubated for 2 h with QD-1 $(200 \mu \mathrm{g} / \mathrm{mL})$ and $\mathbf{1}(10 \mu \mathrm{g} / \mathrm{mL})$, followed by extensive PBS washes, and imaged immediately thereafter in the imaging buffer.

\section{ASSOCIATED CONTENT}

\section{Supporting Information}

The Supporting Information is available free of charge on the ACS Publications website at DOI: 10.1021/acsomega.8b00633.

Synthesis and characterization of compounds; synthesis and characterization of compounds 1, 5-13; synthesis of QDs-1 and characterization of QDs; confocal microscopy; toxicity assays; ${ }^{1} \mathrm{H}$ spectrum for $\mathrm{QD}-70 \mathrm{COOH}$; ${ }^{1} \mathrm{H}$ spectrum for QD-1; absorbance spectrum for QD-1; fluorescence spectrum for QD-1; fluorescence spectrum for QD-1; confocal microscopy images of HeLa cells; confocal microscopy images MCF-7 cells; confocal microscopy images of an MDA-MB-32 cell Z-stack section; confocal microscopy images and fluorescent overlap with bright field of MCF-7, MDA-MB-231, and HeLa cells; fluorescent intensity of QD-1 (QD-MMPI)treated and QD-1/1 (QD-MMPI/MMPI)-treated MDA, MFC7, and HeLa cells; and effects of $\mathbf{1}$ and QD-1 on viability and metabolic competence (PDF)

\section{AUTHOR INFORMATION}

\section{Corresponding Authors}

*E-mail: m.c.galan@bristol.ac.uk. Phone: +44(0)1179287654 (M.C.G.).

*E-mail: cristina.nativi@unifi.it. Phone: +39-0554573540 (C.N.).

ORCID

Barbara Richichi: 0000-0001-7093-9513

Marco Fragai: 0000-0002-8440-1690

M. Carmen Galan: 0000-0001-7307-2871

Cristina Nativi: 0000-0002-6312-3230

Author Contributions

"B.R. and V.B. equally contributed to the work. 


\section{Notes}

The authors declare no competing financial interest.

\section{ACKNOWLEDGMENTS}

We are grateful to Prof. Claudio Luchinat (University of Florence) for the fruitful discussions. Authors thank COST Action "MultiGlycoNano", CM1102 for GS's STSM fellowship. MCG thanks EPSRC CAF EP/L001926/1 (MCG), ERCCOG: 648239, and the Bristol Wolfson Bioimaging Facility.

\section{ADDITIONAL NOTE}

${ }^{a}$ As reported above (see Introduction, $)$, MMPs' active sites are closely similar and able to adjust hosting also ligands designed for a specific member of the family. Thus, the inhibition constant of 1 was assessed toward MMP-12, which is remarkably more stable than MMP-14; MMP-14 instability might have affected the measurements.

\section{REFERENCES}

(1) Whittaker, M.; Floyd, C. D.; Brown, P.; Gearing, A. J. H. Design and therapeutic application of matrix matalloproteinase inhibitors. Chem. Rev. 1999, 99, 2735-2776.

(2) Tauro, M.; McGuire, J.; Lynch, C. C. New approaches to selectively target cancer-associated matrix metallproteinases activity. Canc. Metastasis Rev. 2014, 33, 1043-1057.

(3) Dormán, G.; Cseh, S.; Hajdú, I.; Barna, L.; Kónya, D.; Kupai, K.; Kovács, L.; Ferdinandy, P. Matrix metalloproteinase inhibitors: a critical appraisal of design principles and proposed therapeutic utility. Drugs 2010, 70, 949-964.

(4) Coussens, L. M.; Fingleton, B.; Matrisian, L. M. Matrix metalloproteinase inhibitors and cancer: trials and tribulations. Science 2002, 295, 2387-2392.

(5) Calderone, V.; Fragai, M.; Luchinat, C.; Nativi, C.; Richichi, B.; Roelens, S. A high-affinity carbohydrate-containing inhibitor of matrix metalloproteinases. ChemMedChem 2006, 1, 598-601.

(6) Attolino, E.; Calderone, V.; Dragoni, E.; Fragai, M.; Richichi, B.; Luchinat, C.; Nativi, C. Structure-based approach to nanomolar, water soluble matrix metalloproteinases inhibitors (MMPIs). Eur. J. Med. Chem. 2010, 45, 5919-5925.

(7) Chun, T.-H.; Sabeh, F.; Ota, I.; Murphy, H.; McDonagh, K. T.; Holmbeck, K.; Birkedal-Hansen, H.; Allen, E. D.; Weiss, S. J. MT1MMP-dependent neovessel formation within the confines of the three dimensional extracellular matrix. J. Cell Biol. 2004, 167, 757-767.

(8) Jiang, W. G.; Davies, G.; Martin, T. A.; Parr, C.; Watkins, G.; Mason, M. D.; Mansel, R. E. Expression of membrane type-1 matrix metalloproteinases, MT1-MMP in human breast and its impact on invasiveness of breast cancer cells. Int. J. Mol. Med. 2006, 17, 583590.

(9) Yoshida, S.; Takahashi, H. Expression of extracellular matrix molecules in brain metastasis. J. Surg. Oncol. 2009, 100, 65-68.

(10) Bartolomé, R. A.; Ferreiro, S.; Miquilena-Colina, M. E.; Martìnez-Prats, L.; Soto-Montenegro, M. L.; Garcìa-Bernal, D.; Vaquero, J. J.; Agami, R.; Delgado, R.; Desco, M.; Sànchez-Mateos, P.; Teixido, J. The chemokine receptor CXCR4 and the metalloproteinase MT-MMP are mutually required during melanoma metastasis to lung. Am. J. Pathol. 2009, 174, 602-612.

(11) Sohail, A.; Sun, Q.; Zhao, H.; Bernardo, M. M.; Cho, J.-A.; Fridman, R. MT4-(MMP17) and MT6-MMP(MMP25), a unique set of membrane-anchored matrix metalloproteinases: properties and expression in cancer. Canc. Metastasis Rev. 2008, 27, 289-302.

(12) Schafers, M.; Schober, O.; Hermann, S. Matrix-metalloproteinases as imaging targets for inflammatory activity in atherosclerotic plaques. J. Nucl. Med. 2010, 51, 663-666.

(13) Devy, L.; Huang, L. L.; Naa, L.; Yanamandra, N.; Pieters, H.; Frans, N.; Chang, E.; Tao, Q.; Vanhove, M.; Lejeune, A.; van Gool, R.; Sexton, D. J.; Kuang, G.; Rank, D.; Hogan, S.; Pazmany, C.; Ma, Y. L.; Schoonnbroodt, S.; Nixon, A. E.; Ladner, R. C.; Hoet, R.;
Henderikx, P.; TenHoor, C.; Rabbani, S. A.; Valentino, M. L.; Wood, C. R.; Dransfield, D. T. Selective inhibition of matrix metalloproteinases-14 blocks tumor growth, invasion and angiogenesis. Cancer Res. 2009, 69, 1517-1526.

(14) Schröpfer, A.; Kammerer, U.; Kapp, M.; Dietl, J.; Feix, S.; Anacker, J. Expression pattern of matrix metalloproteinases in human gynecological cancer cell lines. BMC Cancer 2010, 10, 553.

(15) Michalet, X.; Pinaud, F. F.; Bentolila, L. A.; Tsay, J. M.; Doose, S.; Li, J. J.; Sundaresan, G.; Wu, A. M.; Gambhir, S. S.; Weiss, S. Quantum dots for live cells, in vivo imaging and diagnostics. Science 2005, 307, 538-544.

(16) Wang, Y.; Chen, L. Quantum dots, lighting up the research and development of nanomedicine. Nanomedicine 2011, 7, 385-402.

(17) Verkade, P. Moving EM: the rapid transfer system as a new tool for correlative light and electron microscopy and high throughput for high-pressure freezing. J. Microsc 2008, 230, 317-328.

(18) Polishchuk, R. S.; Polishchuk, E. V.; Luini, A. Correlative LightElectron Microscopy as a Tool to Study in Vivo Dynamics and Ultrastructure of Intracellular Structures; Springer Science+Business Media, LLC, 2013; Vol. 931.

(19) Hou, B.; Benito-Alfonso, D.; Webster, R.; Cherns, D.; Galan, M. C.; Fermin, D. J. Rapid phosphine-free synthesis of CdSe quantum dots: promoting the generation of Se precursors using a radical initiator. J. Mater. Chem. A 2014, 2, 6879-6886.

(20) Hou, B.; Benito-Alifonso, D.; Kattan, N.; Cherns, D.; Galan, M. C.; Fermin, D. J. Initial stages in the formation of $\mathrm{Cu}_{2} \mathrm{ZnSn}(\mathrm{S}, \mathrm{Se})_{4}$ nanoparticles. Chem.-Eur. J. 2013, 19, 15847-15851.

(21) Benito-Alifonso, D.; Tremel, S.; Hou, B.; Lockyear, H.; Mantell, J.; Fermin, D. J.; Verkade, P.; Berry, M.; Galan, M. C. Lactose as a "Trojan horse" for quantum dots cell transport. Angew. Chem., Int. Ed. 2014, 53, 810-814.

(22) Hill, S. A.; Benito-Alifonso, D.; Morgan, D. J.; Davis, S. A.; Berry, M.; Galan, M. C. Three-minutes synthesis of sp3 nanocristalline carbon dots as non-toxic fluorescent platforms for intracellular delivery. Nanoscale 2016, 8, 18630-18634.

(23) Bartoloni, M.; Domìnguez, B. E.; Dragoni, E.; Richichi, B.; Fragai, M.; André, S.; Gabius, H.-J.; Ardà, A.; Luchinat, C.; JiménezBarbero, J.; Nativi, C. Targeting matrix metalloproteinases: design of a bifunctional inhibitor for presentation by tumor-associated galectins. Chem.-Eur. J. 2013, 19, 1896-1902.

(24) Egawa, N.; Koshikawa, N.; Tomari, T.; Nabeshima, K.; Isobe, T.; Seiki, M. Membrane type 1 matrix metalloproteinases (MT1MMP/MMP-14) cleaves and release a $22-\mathrm{kDa}$ extracellular matrix metalloproteinase inducer (EMMPRIN) fragment from tumor cells. J. Biol. Chem. 2006, 281, 37576-37585.

(25) Direct conjugation of $\mathbf{1}$ to QD-70COOH resulted in nanoparticles that aggregated and precipitated within minutes. 